As a teacher I cannot help being concerned by the haphazard state of our postgraduate training arrangements, and by the way trainees are exploited in nonteaching hospitals to help run the National Health Service on the cheap. The undergraduate comes to the university proposing frankly to give nothing but intelligence and enthusiasm to the study of his subject, and simply for that subject's sake ; his time is at our disposal and ours at his. The postgraduate student is an employee of the National Health Service-and he who pays the piper calls the tune.-I am, etc.,

Nuffield Department of Anaesthetics, JAMES PARKHOUSE. Oxford.

\section{Shortage of Doctors}

SiR,-Dr. J. R. Seale (December 9, p. 1554) has produced some interesting statistics, and maybe these show that there is a shortage of doctors if the sole criterion adopted is our present numbers relative to the population as compared with previous years. This will lead us sadly astray if account is not also taken of our present greatly changed pattern of medical requirements. Before we start on any recruitment drive, before we can decide on how many doctors we need, we must have much more operational research on the content of the doctor's day in all branches of medicine in different parts of the country. What we want more than anything is a scientific appraisal uninfluenced by the emotional attitudes and prejudices which too often bedevil discussion of the Health Service.

The public image of the doctor is that he is a being nard worked and rushed off his feet at all times, but apart from epidemics is this really true? And, if so, could this not be largely avoided by better organization? Should we not also pause for a moment and ask what we are rushing about for? How much of the work we are doing requires a qualified doctor? Should we not make more use of medical auxiliaries and social workers joining in the team-work which is so essential to-day? Is it not wasteful to employ qualified doctors in purely administrative duties, and are all those committees which consume a good deal of the time of many G.P.s and consultants really necessary ?

As far as general practice is concerned the only major change which the 1948 take-over brought was in our method of remuneration; for the most part it is run very much as before. Do we still need two or three consulting sessions daily? Surely one would be enough, in the mornings by appointment, so that afternoons would be left free for visits or hospital or industrial appointments. It is true that occasionally we have free time in the afternoons, but as this is not regular and usually unexpected and we are on call anyway it is of little value, while the evening surgery leaves us too tired for much activity afterwards. We, too, should finish our working day by 6 p.m., and an emergency rota system organized by ourselves would operate until 7 a.m. with special arrangements for maternity work, week-ends, sickness, and holidays.

All these require much better organization than we have now. The day of the single-handed G.P. is passing and modern conditions make it much more rewarding to practise in groups from communal premises. call them what you will. Premises shared by groups of G.P.s working together would ensure the most economic use of nursing and secretarial assistance and would greatly facilitate their taking over the clinical work of the local health authority. Some diagnostic appliances would also increase the range and interest of their work. and with all these aids "buying time" for us we should be able to look after many more patients than the present maximum. All these facilities should be provided for us on regional board level in the same way as for consultants. I see no reason whatsoever why we should be expected to pay for them ourselves.

As to why so many doctors emigrate each year the reason is surely more complex than mere dissatisfaction with the Health Service. Nationalized medicine. pioneered in this country, will ultimately spread to most civilized communities, even to the U.S.A. and Canada. despite determined opposition. In our preoccupation with our own interests we should not forget that the National Health Service was instituted for the benefiı of the people as a whole, and, as someone said of another profession, medicine is far too serious a business to be left solely to the doctors. - I am, etc.,

Bristol 4. Joseph SLugletT.

\section{Thiazides and Hyperuricaemia}

SIR,-Attention has recently been directed to the subject of thiazide-induced hyperuricaemia, and the inference made that this is a harmful complication and might logically be averted by the concurrent administra. tion of a uricosuric agent. ${ }^{12}$ This communication is a preliminary report concerning observations made on 75 patients receiving hydrochlorthiazide or chlorthiazide in dosage equivalents of 0.5 to 1 gramme of the latter daily. Our experience includes working with several chemical methods including the conventional colorometric determinations (Carraway; and Folin, Brown. and Denis) as well as the enzymatic technique.

The results of this study focus attention on the difficulty in arriving at any definite conclusions concerning influences on serum uric acid levels for the following reasons: (1) There are marked differences in values obtained using different techniques; (2) there is great intrinsic biologic variation in the same patient which may depend upon diurnal factors, diet, emotions. concomitant medications, ${ }^{3}$ altered states of renal function, and concurrent disease ; (3) there is apparent significant variability in terms of population studied both in respect to race, sex, age, and other hereditary factors. In addition, it is becoming increasingly apparent that the values for a so-called normal serum uric acid level may have to be revised upward. In our studies $25 \%$ of males and $20 \%$ of females in a control hospital population had one or more uric acid values in excess of $6 \mathrm{mg} . \%$. Finally the implication that alleged thiazide-induced hyperuricaemia is harmful to the individual deserves careful scrutiny in view of the widespread use of this agent and the paucity of welldocumented cases of actual gout attributable to thes? agents alone. No cases of gout occurred in our series on the dosage employed, and administration of hydrochlorthiazide $100 \mathrm{mg}$. daily failed to induce gout in a series of eight gouty patients to whom no uricosuric agent was simultaneously given.

It is conceivable that many patients on thiazides who have joint pains and uric acids above $6 \mathrm{mg} . \%$ are considered to have gout, but this combination of factors does not permit one to reach this conclusion in our opinion.

Briefly, our observations suggest the hyperuricaemia seen with thiazides is related to dosage employed and 
the control level of uric acid, with greater rises seen in those patients with control levels above $6 \mathrm{mg} . \%$. As mentioned above, a significant percentage of the hospital population showed serum uric acids in excess of $6 \mathrm{mg} . \%$, and random uric acids obtained on patients on long-term thiazide therapy (six months or longer) showed no significant statistical difference from the control group. Finally, careful seriatim observations on the same patient suggest that the initial elevation seen with thiazides is a relatively transient phenomenon and when the same patient is studied for four to twelve weeks a tendency is seen for the return of uric acid to control levels in many patients.

We have not been impressed with any somatic complaints or clinical differences between patients with high uric acids compared with those with low or normal values. In one case that developed renal calculus during hyperuricaemia, analysis of the stone revealed that it was composed of calcium oxalate. On the other hand, the suggestion that hyperuricaemia is damaging and should be averted by concurrent administration of a uricosuric agent should be received with some trepidation, since it appears likely that this would be attended by a considerable incidence of renal lithiasis as well as some mitigation of the natriuretic effect of the agent used. ${ }^{4}$-We are, etc.,

Endocrine and Metabolic Services, PaUl J. Roscir. City Hospital, Elmhurst, L.I., New York. Martin F. Sturman.

\section{REFERENCES}

1 Brit. med. J., 1960, $2,45$.

2 Dixon, A. St. J., and Treadwell, B. L. J., ibid., 1960, 2, 232. Crayzel, A. I., Liddle, L., and Seegmiller, J. E., New Engl. J. Med., 1961, 265, 763.

- Forsham, P., personal communication.

\section{" A Pretty Ghastly', 'Awful Picture"}

SIR,-In regard to the correspondence on the "Pretty Ghastly, Awful Picture," I am in agreement with Dr. W. A. Lister (December 30, p. 1778) in his remarks regarding the capitation system of payment in the N.H.S. This in my opinion, having been in general practice for the past 26 years, is the root cause of the present trouble and the reason why medical graduates strive for specialist posts or emigrate rather than enter general practice.

The capitation system is legalized medical bondage and has produced a definite lowering of medical standards because it gives no incentive to increase our items of service to patients. There is no doubt also that it has brought about a defensive attitude on the part of the doctor because of the trivial demands made by so many patients. Such demands were, of course, made before the advent of the N.H.S., but it made all the difference when a fee was received for it. It is part of ordinary human nature to work better at all times if a fee is paid for each item of service given and is a stimulus to give more of one's time and thought to increase one's income. The capitation system, the inability to move from one area to another, the fear of litigation if we do not comply with a patient's whims and demands - these are the root cause of this evil.

I do not agree with Dr. Lister that a salaried service is the answer, rather I would see a fair fee-for-service, payment which the doctor would be at liberty to increase if the circumstances and the patient's financial status warranted it. Under this system the patient would have complete freedom of choice of doctor at all times, no doctor would be legally liable for 24 hours of the day for any person unless under treatment at the time, and hard work would receive its due reward. There would also be much more freedom to move than at present.

Given these conditions, there would be no lack of recruits to enter general practice and medical men in this country would regain their professional dignity, gratitude in the eyes of the public, and peace of mind, all of which are fast being lost to us.-I am, etc.,

$$
\text { Horley, Surrey. } \quad \text { T. R. F. RAW. }
$$

\section{Thrush in the Newborn}

SiR,-Dr. H. Shrand's interesting paper (December 9, p. 1530) contains suggestions that probably gentian violet should be tried first, keeping nystatin for resistant cases, and refers to the possible emergence of nystatinresistant strains. I am wondering if nystatin-resistance has been encountered in any significant degree. In our laboratory studies it has been found extremely difficult to induce any appreciable order of resistance by Candida albicans through repeated subculturing, and we have not so far isolated from human or animal sources any strains naturally resistant to nystatin.

The published results of other investigators suggest that few strains of $C$. albicans have natural or acquired resistance to nystatin. Stewart ${ }^{1}$ reported that over 100 strains of Candida, isolated from various lesions or sources, were sensitive and that resistance was not seen after passage in vitro or on re-isolation during and after treatment. Jennison et al..$^{2-5}$ tested many hundreds of strains and found them to be sensitive, and more recently Brodie and Henderson ${ }^{6}$ isolated 500 strains of Candida species and reported that all were sensitive to nystatin in vitro. Graham ${ }^{7}$ found that nystatin was better than gentian violet for the treatment of oral thrush, and since this infection is a potential threat to the infant, as Dr. Shrand points out, it would seem unwise to withhold the most effective agent on hypothetical grounds that resistance might be produced. -I am, etc.,

Clinical Research Department,

E. R. Squibb \& Sons, London W.1.

\section{W. W. Heseltine.}

\section{REFERENCES}

1 Stewart, G. T., Brit. med. L., 1956, 1, 658.

2 Jennison, R. ̈. F., and Llywelyn-Jones, J. D., ibid., 1957, 1, 145. 3 ibid, 1957, 1, 517.

- Z and Stenton, P., J. clin. Path., 1957, 10, 219.

5 - in Fungous Diseases and Their Treatment, 1958, p. 221. Edited by R. W. Riddell and G. T. Stewart. Butterworth, London.

- Brodie, J.. and Henderson, A., Scot. med. J., 1961, 6, 146.

"Graham, R. D., Lancet, 1959, 2, 600.

\section{Severe Reaction to Meprobamate}

SIR,-We too have observed alarming collapse following ingestion of a small dose of meprobamate (Dr. C. A. H. Watts, November 18, p. 1360).

A Persian male aged 30 years took his first tablet of "miltown" (meprobamate), $400 \mathrm{mg}$., on the morning of November 12, 1961. Within two hours he became faint, cold, and shivery, and bright red weals appeared on his skin. He was admitted to hospital in a state of collapse with a pulse rate of 120 per minute and a blood-pressure of $90 / 70$. After an injection of adrenaline, $0.25 \mathrm{mg}$., and of promethazine, his condition began to improve and he continued on diphenhydramine (" benadryl "), $50 \mathrm{mg}$. t.i.d. By the third day his general condition was good, but he was still itching and prednisolone tablets were prescribed. He was discharged on the seventh day. 